\title{
Wind direction sensor based on thermal anemometer for olfactory mobile robot
}

\author{
Helmy Widyantara, Muhammad Rivai, Djoko Purwanto \\ Department of Electrical Engineering, Institut Teknologi Sepuluh Nopember Surabaya, Indonesia
}

\begin{tabular}{l} 
Article Info \\
\hline Article history: \\
Received Sep 19, 2018 \\
Revised Nov 20, 2018 \\
Accepted Dec 4, 2018 \\
\hline
\end{tabular}

Keywords:

Neural network

Olfactory mobile robot

Thermal anemometer

Wind direction sensor

\begin{abstract}
A wind direction sensor has been implemented for many applications, such as navigation, weather, and air pollution monitoring. In an odor tracking system, the wind plays the important role to carry gas from its source. Therefore, the precise, low-cost, and effective wind direction sensor is required to trace the gas source. In this study, a new design of wind direction sensor has been developed using thermal anemometer principle with the main component of the positive temperature coefficient thermistor. Three anemometers each of which has different directions are used as inputs for the neural network to determine the direction of the wind automatically. The experimental results show that the wind sensor system is able to detect twelve wind directions. A mobile robot equipped with this sensor system can navigate to a wind source in the open air with a success rate of $80 \%$. This system is expected to increase the success rate of the olfactory mobile robot in searching for dangerous leaking gas in the open air.
\end{abstract}

Copyright $\odot 2019$ Institute of Advanced Engineering and Science. All rights reserved.

\section{Corresponding Author:}

Muhammad Rivai,

Department of Electrical Engineering,

Institut Teknologi Sepuluh Nopember Surabaya, Indonesia.

Email: muhammad_rivai@ee.its.ac.id

\section{INTRODUCTION}

The measurements of wind direction are commonly used in weather monitoring stations, navigation systems, and air pollution systems $[1,2]$. This data is required in many areas, such as aviation, shipping, agriculture, etc. In pollution systems, the wind direction is used for analysis of the spread of air pollutants [3,4], especially in industrial area with neighboring residence.Wind direction is also used as auxiliary device to make the takeoff process of Unmanned Aerial Vehicle (UAV) smoother [5], and as a navigation system on odor tracking robot [6].

In the odor tracking robot, the wind plays a role to carry the odor from its source [3]. The odor moves from the source occurs by advection and diffusion assisted by the wind. The odor plume spreads to fill the space following the wind direction as illustrated in Figure 1 [7]. Several methods of odor plume tracking have been tested and compared its performance by previous researchers. Li et al concluded that the zigzag method was efficient only if the robot moves faster than the odor plume or air flow. The upwind method could be better if the robot moves slower than the odor plume [3]. However, the previous proposed method has not been successful in tracing the odor plume in open air and in turbulent wind conditions. Unstable wind conditions cause the direction of spreading the odor plume is changed, this causes the robot to lose tracking of the odor plume. Therefore, the search for the odor source is unsuccessful or takes a long time to find the odor plume. Alexander et al considered the wind direction in his method for tracking odor plume in turbulence condition [8]. The tracking success rate increases to $80 \%$ in the simulation. This result emphasizes that the present of wind direction sensor is necessary for odor plume tracking in real plants. By knowing the wind direction, the tracking process can be accomplished faster and easier to find the gas source. In this study, we propose a wind direction sensor using an omnidirectional thermal anemometer. This sensor system 
is expected to be implemented in various unmanned devices, such as odor tracking robot or gas leakage finder robot $[9,10]$, for either single [11] or swarm type robots [12-14].

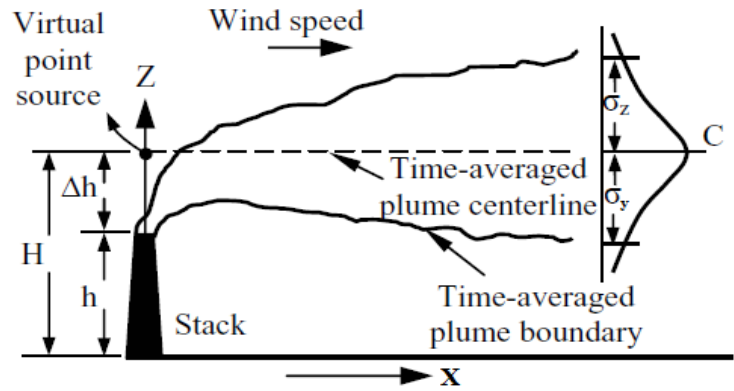

Figure 1. The odor plume dispersion

\section{RESEARCH METHOD}

\subsection{Thermal Anemometer}

Anemometer is a device to measure the wind speed. Based on its working principle, there are two types of this device, i.e. velocity and pressure anemometers. However, the velocity anemometer is more commonly used in many applications. Thermal anemometer is a type of velocity anemometer that converts wind speed to temperature changes. In this method, when the air is passing through the wire or transducer's surface, it will induce the cooling effect [15]. The different magnitude of the temperature is then converted into wind speed. Thermal anemometer has high frequency response and good spatial resolution compared to the other methods. Therefore, it is broadly used for turbulent wind analysis.

The thermal anemometer is shown in Figure 2. Generally, the core element of the thermal anemometer is a thin wire known as hot wire or a transducer such as a thermistor, resistive temperature detectors (RTD), etc. The thermal anemometer has general working principle i.e., when the transducer is supplied by an electrical current, it will generate the internal heating which equals to its surroundings $[16,17]$. The amount of input power is equal to the lost power affected by the convective heat transfer expressed as:

$$
I^{2} R_{W}=h \cdot A_{W}\left(T_{W}-T_{f}\right)
$$

Where $I$ is the input current, $R_{w}$ is the resistance of the transducer, $h$ is the heat transfer coefficient of the transducer, $A_{w}$ is the transducer's surface area, $T_{w}$ is the transducer temperature, $T_{f}$ is the temperature in the air, and $R_{w}$ is the function of temperature derived as:

$$
R_{W}=R_{R e f}\left[1+\alpha\left(T_{W}-T_{R e f}\right)\right]
$$

Where $\alpha$ is the coefficient of thermal resistance, $T_{\text {Ref }}$ is the reference temperature, and $R_{\text {Ref }}$ is the resistance at the reference temperature [18]. According to King's law, the heat transfer coefficient symbolized by $h$ is the function of fluid velocity $V_{f}$, wherein $a, b$, and $c$ are the coefficient achieved from the calibration $(c \sim 0.5)$.

$$
h=a+b \cdot V_{f}^{c}
$$

By combining the equation (1), (2), and (3), we can eliminate $h$.

$$
\begin{aligned}
& a+b \cdot V_{f}^{c}=\frac{I^{2} R_{w}}{A_{w}\left(T_{w}-T_{f}\right)} \\
& =\frac{I^{2} R_{R e f}\left[1+\alpha\left(T_{w}-T_{R e f}\right)\right]}{A_{w}\left(T_{w}-T_{f}\right)}
\end{aligned}
$$

Therefore, the fluid velocity can be written as:

$$
V_{f}=\left\{\left[\frac{I^{2} R_{R e f}\left[1+\alpha\left(T_{w}-T_{R e f}\right)\right]}{A_{w}\left(T_{w}-T_{f}\right)}-a\right] / b\right\}^{1 / c}
$$




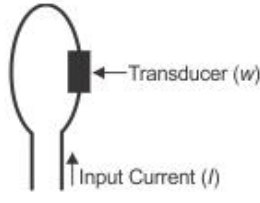

(a)

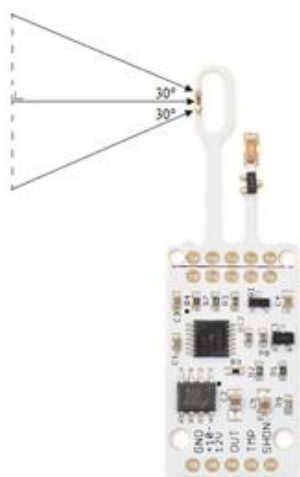

(b)

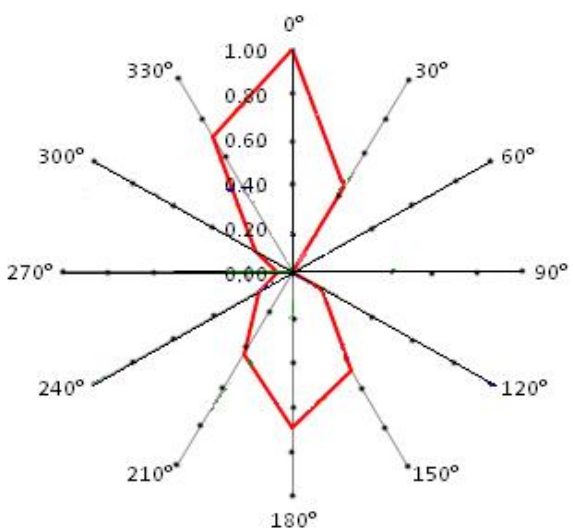

(c)

Figure 2. Thermal anemometer: (a) the working principle, (b) Wind RevP sensor, and

(c) characteristic of the Wind RevP sensor

\subsection{Wind Tunnel}

The wind tunnel is used to minimize the effects of turbulence, to maintain the stable airflow, and also to produce the homogeneous airflow $[19,20]$. The wind tunnel is applied to achieve the wind sensor characteristics, and also to verify the experimental results. The design of the wind tunnel is shown in Figure 3 . The wind tunnel used in this experiment consists of a chamber with the sizes of $15 \mathrm{~cm} \mathrm{x} 18 \mathrm{~cm} \mathrm{x} 18 \mathrm{~cm}$. It has the entry and the exit holes with the same diameter of $18 \mathrm{~cm}$. There are six thin fins installed at the exit hole to minimize the turbulence effect. Furthermore, the diffuser of plastic straw located at the entry channel has the length of $15 \mathrm{~cm}$ and diameter of $0.7 \mathrm{~cm}$. The air coming from the outside already rectified by the diffuser is transported to the testing area with the size of $0.6 \mathrm{~m} \times 0.4 \mathrm{~m} \times 0.4 \mathrm{~m}$. In this study, the wind tunnel operates from 0.5 to $7 \mathrm{mph}$, with the voltage supply is varied from 7.5 volts to 24 volts.

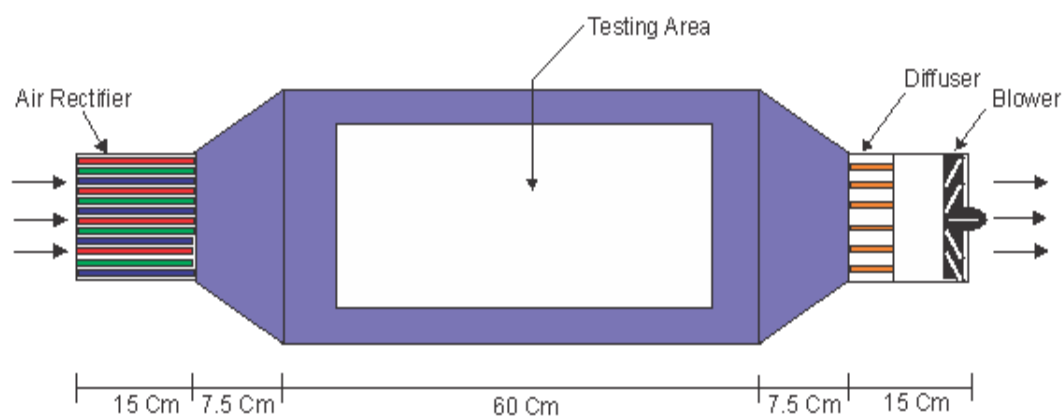

Figure 3. The design of wind tunnel

\subsection{Wind Direction Sensor}

This study uses a thermal anemometer based wind speed sensor of Wind RevP produced by Modern Device. It applies a positive temperature coefficient (PTC) thermistor as the transducer to measure the cooling effect caused by the air passing through the transducer's surface. It is able to measure the wind speed from 0 to $150 \mathrm{mph}$ [21], with the accuracy of $0.5 \mathrm{mph}$ [22]. Furthermore, the relationship between the voltage and temperature can be expressed as:

$$
V_{\text {out }}=a+b T+c v^{d}
$$

where $T$ is ambient temperature $\left({ }^{\circ} \mathrm{C}\right), v$ is wind speed $\left(\mathrm{ms}^{-1}\right)$, and a, b, c, d are constants. The transpose of wind speed can be written as: 


$$
v=\left\{\frac{\left(V_{\text {out }}-a-b T\right)}{C}\right\}^{1 / d}
$$

The output signal of the Wind RevP is then converted into digital data using Analog to Digital Converter (ADC) of the microcontroller. The characteristic data of the Wind RevP assessed by the wind tunnel can be seen in Figure 2(c). It shows that the wind sensor provides the different responses for each sensor to the wind direction. This data is performed using a wind speed of 1.5 , 3 , and $6 \mathrm{mph}$ with normalization expressed as:

$$
\text { Xnew }=\frac{(X-X \min )}{(X \max -X \min )}
$$

According to experimental result, the wind sensor has the highest output at the direction of $0^{\circ}$ and the lowest output at the direction of $90^{\circ}$, and $270^{\circ}$. Meanwhile, for the opposite direction such as $0^{\circ}$ and $180^{\circ}$, the wind sensor provides similar output. Therefore, to obtain the precise wind direction modeling, an advanced method and appropriate sensor placement are required.

According to the sensor characteristic, the wind sensor has a good sensitivity in the measurement angle of $60^{\circ}$. In order to recognize 12 wind directions, the configuration of three sensors defined with A, B, and $\mathrm{C}$ should be located at $0^{\circ}, 120^{\circ}$, and $240^{\circ}$, respectively. The sensor configuration is shown in Figure 4. The small size of anemometers are required for mobile robot applications such as swarm robotics. According to the mechanical design, if the base diameter of the wind direction sensor is smaller than $20 \mathrm{~cm}$, it will generate the similar responses due to the short distance.

The schematic layout of the wind direction sensor shown in Figure 4(a) uses the omnidirectional method applying the acrylic material with a thickness of $0.5 \mathrm{~cm}$. Figure 4(b) presents the mechanical design of the wind direction sensor. Each sensor is connected to the microcontroller. The data retrieval process is conducted using the wind tunnel at the wind speed of $1.5 \mathrm{mph}, 3 \mathrm{mph}$, and $6 \mathrm{mph}$ for the specific wind directions by rotating the sensor every $30^{\circ}$.

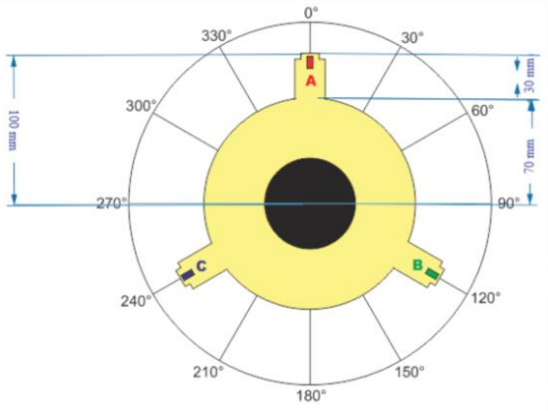

(a)

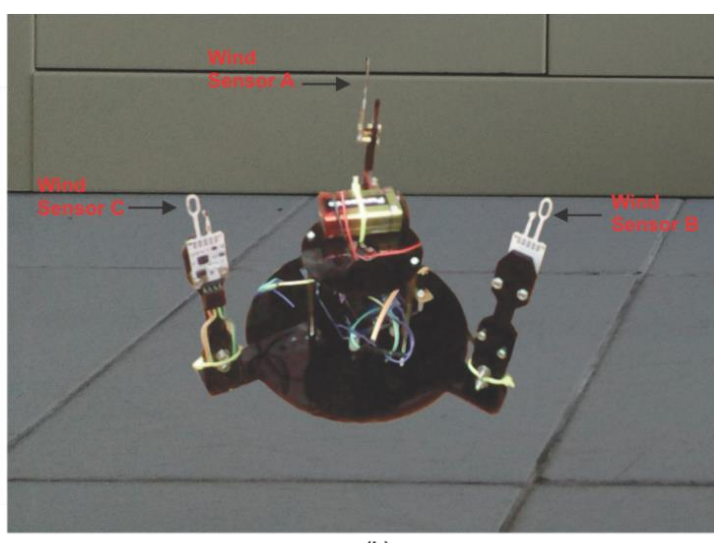

(b)

Figure 4. Wind direction sensor: (a) the schematic layout, and (b) the mechanical design

\subsection{Neural Network for Wind Direction Prediction}

In this study, a Multi Layer Perceptron (MLP) neural network algorithm is applied to predict the wind direction. The MLP is a perceptron model developed by Rosenblattin [23]. Perceptron model is used to solve linear problems only, whereas MLP can be used to accomplish complex problems. The MLP is a perceptron that has the additional layers between the input layer and the output layer known as the hidden layer. The architecture of MLP network used in this study can be seen in Figure 5. The input layer nodes denoted by X1, X2, and X3 obtain data from wind speed sensors A, B, and C, respectively. A number of twenty neurons in the hidden layer are used to improve the network performance as a pattern identifier. 


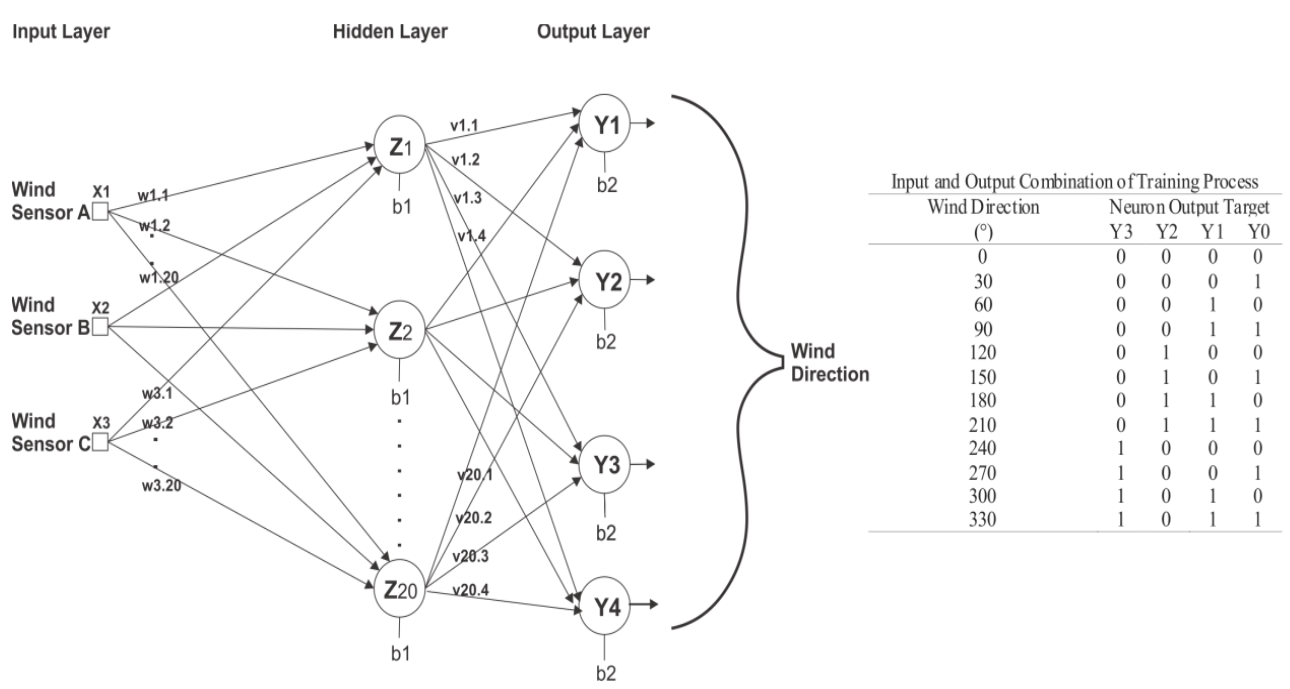

Figure 5. The architecture of neural network

The four neurons in the output layer represent the twelve wind directions. The activation function used in this study is the binary sigmoid function [23, 24]. Backpropagation is a learning algorithm for the artificial neural network to obtain proper weights between the neurons [25]. In this method, the weights of the hidden and output layers are updated iteratively during the learning process [26]. The back propagation algorithm consists of advanced feed forward computation and back propagation. The feed forward in hidden layer is expressed by:

$$
Z_{n e t_{j}}=w_{o j}+\sum_{i=1}^{3} w_{i j} x_{i j}
$$

where $i$ is the $i$-th node $(i=1, . ., 3)$ at the input layer, $j$ is the $j$-th neuron $(j=1,2, \ldots, 20)$ at the hidden layer, $x_{i j}$ is the input value of node $i$ to the hidden neuron $j, w_{o j}$ is the bias of the hidden layer, $w_{i j}$ is the weight between the input node $i$ and the hidden neuron $j$.

The output of each neuron is an activation function expressed as:

$$
Z_{j}=f\left(Z_{n e t_{j}}\right)=\frac{1}{1+e^{-Z_{n e t_{j}}}}
$$

The calculation process is then applied to the output layer expressed as:

$$
y_{n e t_{k}}=v_{O k}+\sum_{j=1}^{k} z_{j} v_{j k}
$$

The value of $v_{o k}$ is the bias at the output layer, $z_{j}$ is the output of each neuron in the hidden layer, and $v_{j k}$ is the weights between hidden neuron $j$ and the output neuron $k(\mathrm{k}=1,2, \ldots, 4)$.

$$
y_{k}=f\left(\text { Ynet }_{k}\right)=\frac{1}{1+e^{- \text {Ynet }_{k}}}
$$

The weight correction between the hidden and the output layers is expressed as:

$$
\begin{aligned}
& \delta_{k}=\left(T_{k}-Y_{k}\right) f^{\prime} Z_{n e t_{j}} \\
& \Delta v_{j k}=\eta \delta_{k} z_{j}
\end{aligned}
$$

where $\eta$ is learning rate. Meanwhile, the weight correction between the input and the hidden layers is expressed as: 


$$
\begin{aligned}
& \delta_{j}=\delta n e t_{j} f^{\prime} Z_{n e t_{j}} \\
& \Delta w_{i j}=\eta \delta_{j} x_{i}
\end{aligned}
$$

The update of weights and bias are given by the following equation:

$$
\begin{aligned}
& v_{j k}=v_{j k}+\Delta v_{j k} \\
& w_{i j}=w_{i j}+\Delta w_{i j}
\end{aligned}
$$

The weights and biases generated in the learning process are then used for the neural network architecture implemented on the microcontroller.

\section{RESULTS AND ANALYSIS}

\subsection{The Analysis of the Wind Direction Sensor}

Characterization and testing of the wind direction sensor are performed inside the wind tunnel as shown in Figure 6(a). Tests on the homogeneity of the wind direction formed in the tunnel need to be accomplished. The test is conducted by turning the fan at $2.700 \mathrm{rpm}$ and measuring the wind speed at various distances inside the tunnel. Figure 6(b) shows that the response of wind speed in the wind tunnel is almost homogeneous.

The configuration of the three sensors presents the performance result as shown in Figure 7. The sensor A has a good response with the wind coming from the direction of $0^{\circ}$ and $180^{\circ}$. The sensor B has a good normalization score with the wind coming from the direction of $120^{\circ}$ and $300^{\circ}$. Meanwhile, sensor C has a good response with the wind coming from the direction of $60^{\circ}$ and $240^{\circ}$. The directivity pattern of the wind sensor is about $60^{\circ}$.

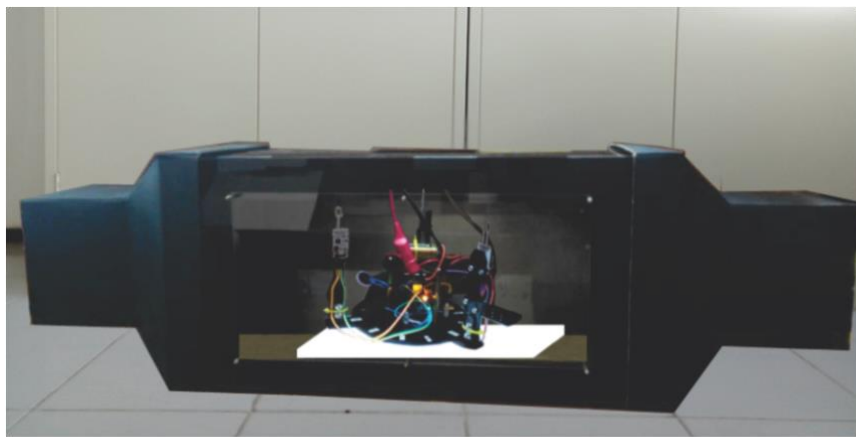

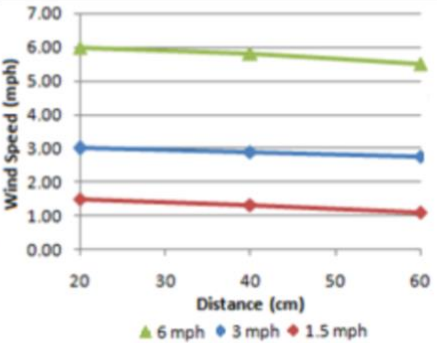

(b)

Figure 6. The characterization and testing of Wind direction sensor: (a) wind tunnel, and (b) homogeneity of the wind inside the tunnel
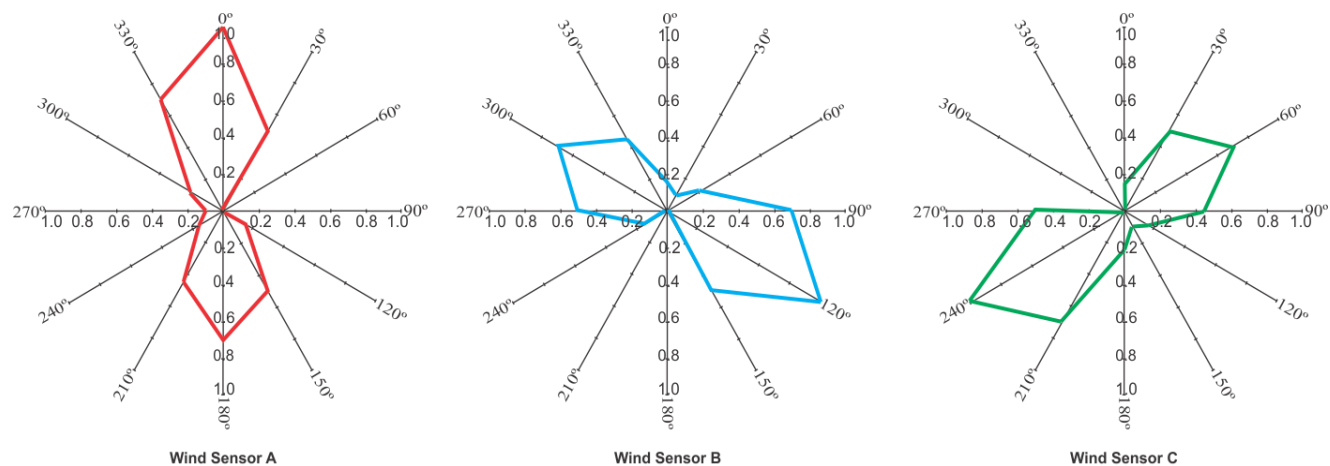

Figure 7. The directivity pattern of the wind sensor 
At the wind direction which has opposite direction of the Wind Sensor Rev P, for instance, the wind coming from the direction of $0^{\circ}$ generates the different normalization score of 0.30 to the direction of $180^{\circ}$. This different result occurs because the position of the thermistor significantly influences the amount of wind stream to reach the thermistor surface. If the wind stream highly reaches the surface, it will generate a faster heat release from the thermistor.The normalized responses of the wind sensor are shown in Figure 8. This indicates that the response pattern of the sensor array is influenced by the airflow coming from different directions. Each wind direction will produce a specific sensor pattern; therefore, it can be used for the training process of the neural network to predict the wind direction.

In the training phase, this network is fed a vector pair consisting of sensor patterns and targets representing twelve wind directions. Each direction consists of ten sensor patterns. The number of iterations in this phase is set at 10,000 epochs, as shown in Figure 9. The testing phase of wind direction sensor is conducted to assess its performance. Test of the sensor module using wind tunnel is performed for twelve wind directions with a speed of $0.5-6 \mathrm{mph}$. The experimental result of the wind direction sensor on the wind tunnel is presented in Table 1. It shows that the accuracy of the wind sensor is $91.6 \%$.

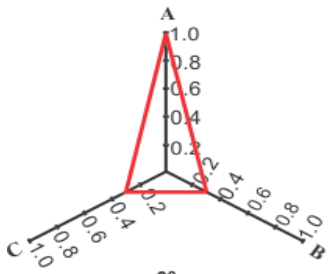

$0^{\circ}$

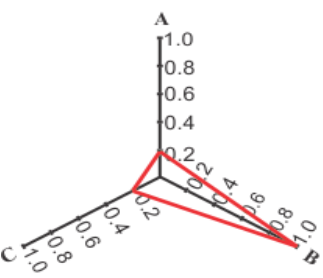

$120^{\circ}$

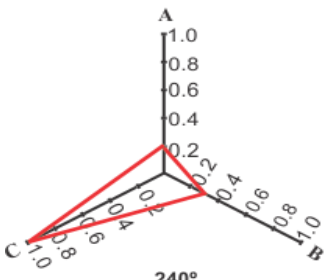

$240^{\circ}$

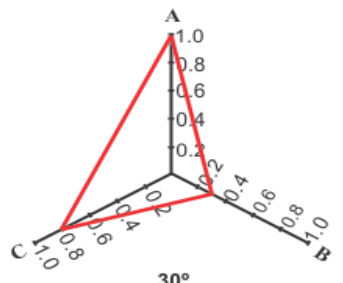

$30^{\circ}$

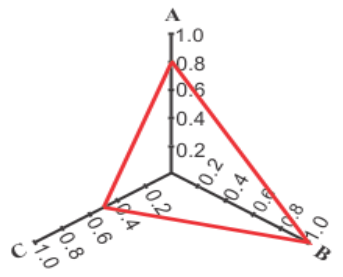

$150^{\circ}$
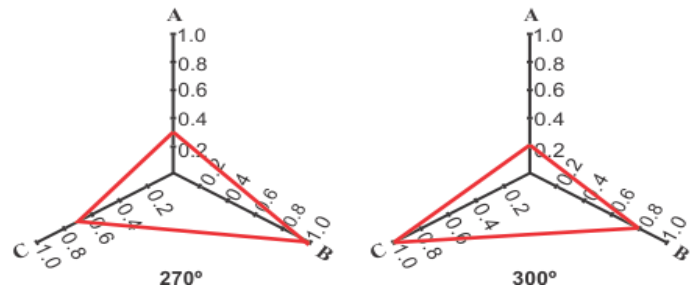

$300^{\circ}$

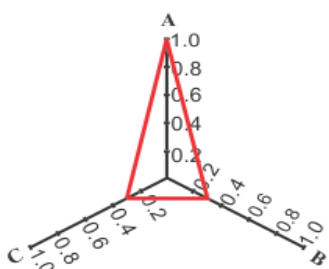

$180^{\circ}$

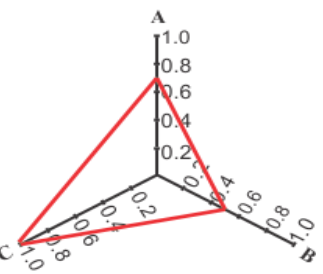

$210^{\circ}$

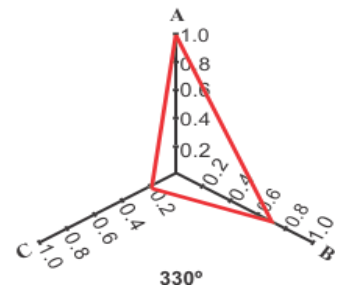

Figure 8 . The responses of the wind sensors

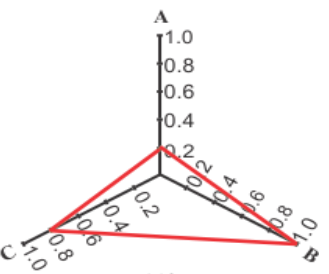

$90^{\circ}$

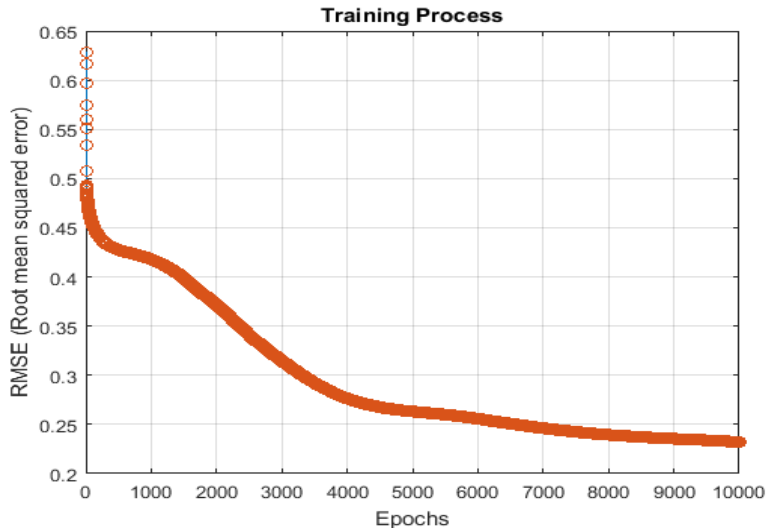

Figure 9. The error values during the training phase 
Table 1. The Measurement Result of the Wind Direction Sensor in the Wind Tunnel

\begin{tabular}{|c|c|c|c|c|c|c|c|c|c|c|c|c|}
\hline Wind Direction & $0^{\circ}$ & $30^{\circ}$ & $60^{\circ}$ & $90^{\circ}$ & $120^{\circ}$ & $150^{\circ}$ & $180^{\circ}$ & $210^{\circ}$ & $240^{\circ}$ & $270^{\circ}$ & $300^{\circ}$ & $330^{\circ}$ \\
\hline Success rate $(\%)$ & 100 & 100 & 70 & 100 & 100 & 100 & 60 & 100 & 100 & 100 & 70 & 100 \\
\hline Average of Success rate $(\%)$ & & & & & & & 91.66 & & & & & \\
\hline
\end{tabular}

\subsection{The Performance of the Olfactory Mobile Robot Equipped with Wind Direction Sensor}

Testing the sensor module in the open air becomes an exciting challenge. In this case, the sensor module is implemented in an olfactory mobile robot to find the wind source. Figure 10 shows implementation of the wind direction sensor on the mobile robot and its tracking algorithm for 1 secondsampling time. The mobile robot is tested with several heading angles. Performance test on the mobile robot in tracking the wind source was accomplished by blowing the wind using an electrical fan, as shown in Figure 11. The robot moves while keep trying to trace the wind toward the fan, as shown in Figure 12. The experimental result of this robot is shown in Table 2. The success rate of the robot to find the source of wind with heading angles of $45^{\circ}, 0^{\circ}$, and $-45^{\circ}$ is $77.5 \%, 87.5 \%$, and $75 \%$, respectively.

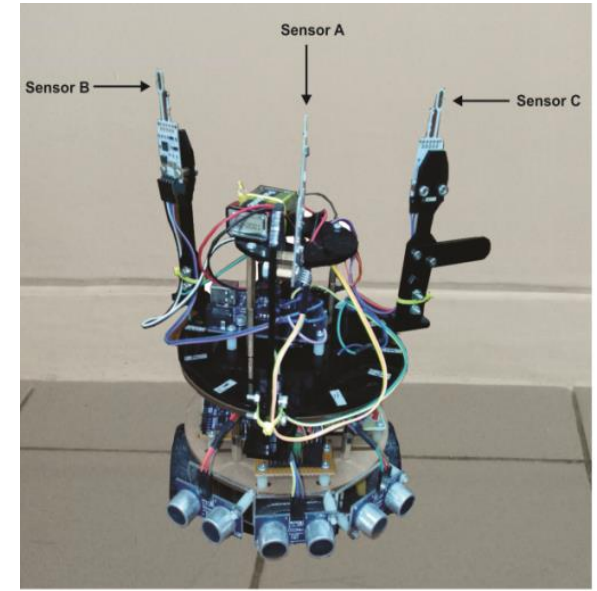

(a)

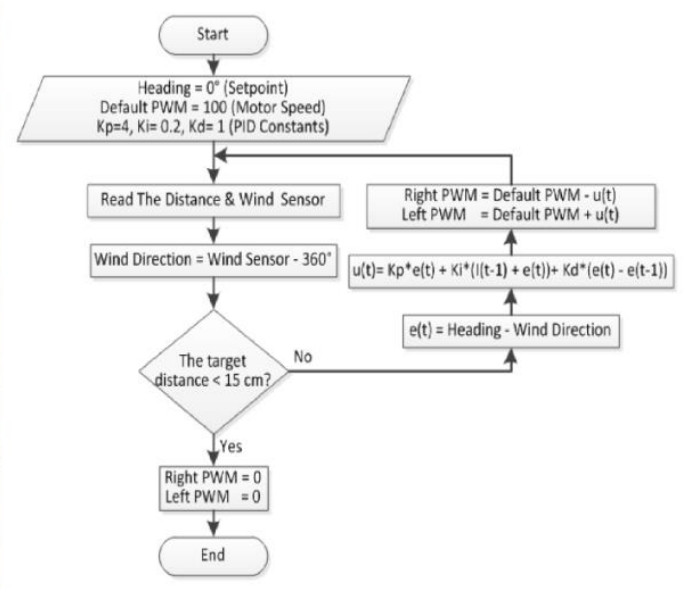

(b)

Figure 10. The implementation of wind direction sensor: (a) mobile robot equipped with the wind direction sensor, and (b) the robot's tracking algorithm

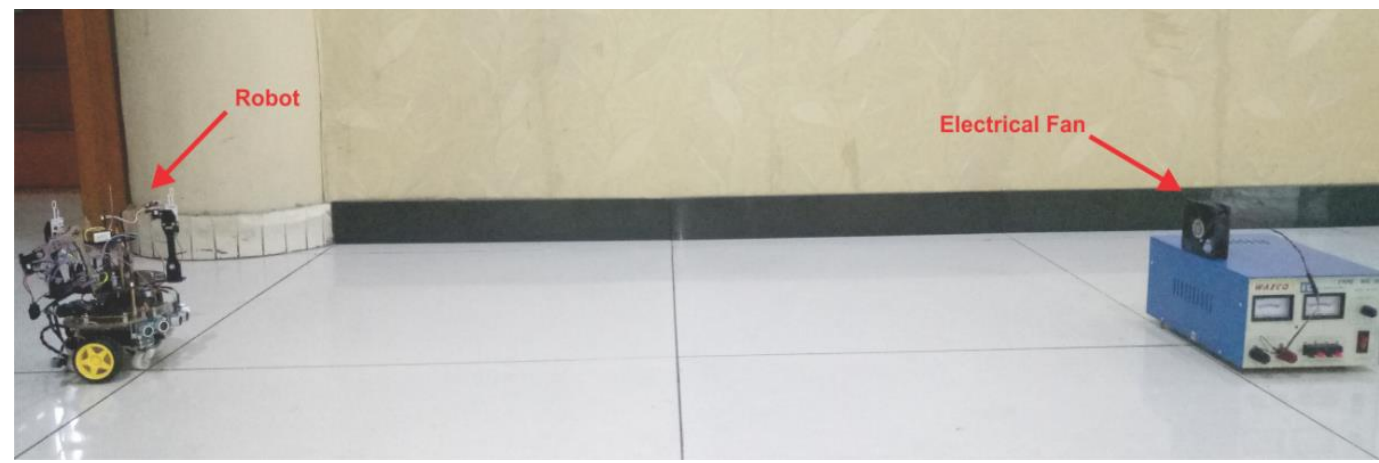

Figure 11. Wind source searching by the olfactory mobile robot

Table 2. The Success Rate of the Robot to Find the Source of Wind

\begin{tabular}{ccccccc}
\hline \multirow{2}{*}{ Orientation } & 25 & 50 & 75 & 100 & Average & Total \\
& & & & & & \\
\hline $45^{\circ}$ & $100 \%$ & $80 \%$ & $70 \%$ & $60 \%$ & $77.5 \%$ & \\
$0^{\circ}$ & $100 \%$ & $100 \%$ & $80 \%$ & $70 \%$ & $87.5 \%$ & $80 \%$ \\
$-45^{\circ}$ & $100 \%$ & $80 \%$ & $70 \%$ & $50 \%$ & $75.0 \%$ & \\
\hline
\end{tabular}




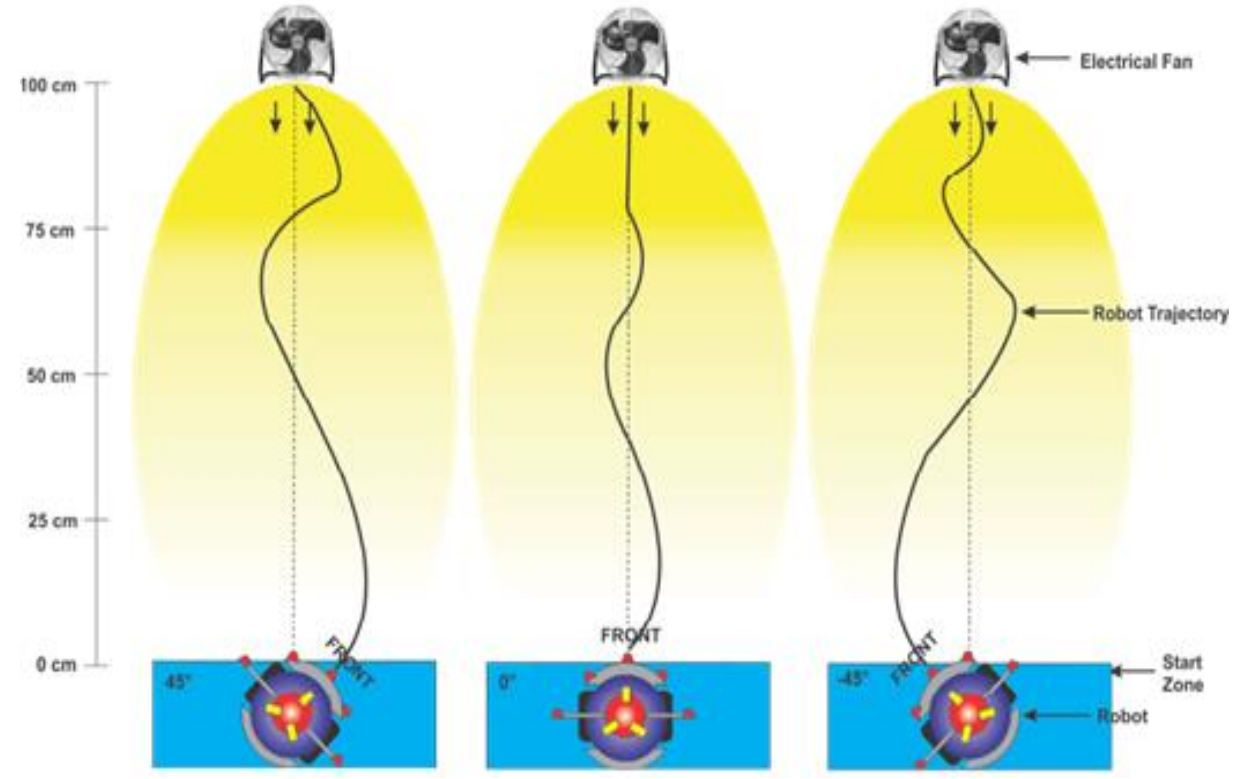

Figure 12. The robot trajectory in search of wind source

\section{CONCLUSION}

In this study, we have developed a wind direction sensor using thermal anemometer principle with the main component of the positive temperature coefficient thermistor. Three anemometers each of which have different directions of $120^{\circ}$ are used as inputs for the neural network to determine the direction of the wind automatically. The experimental results show that the wind sensor system is able to recognize twelve wind directions with the accuracy of $91.6 \%$. An olfactory mobile robot equipped with this sensor system can navigate to a wind source in the open air with a success rate of $80 \%$.

\section{ACKNOWLEDGEMENTS}

This research was carried out with financial aid support from Lembaga Penelitian dan Pengabdian Kepada Masyarakat (LPPM) Institut Teknologi Sepuluh Nopember (ITS) Surabaya, and the Ministry of Research, Technology and Higher Education of the Republic of Indonesia (Kemenristekdikti RI).

\section{REFERENCES}

[1] Babu SD, Acharjya AS, Alam S. Design And Construction of Microcontroller Based Wind Speed And Direction Monitoring System. In Strategic Technology. Cox's Bazar. 2014: 284-288.

[2] Kim KH, Lee SB, DaekwangWoo, Bae GN. Influence of Wind Direction And Speed on The Transport of Particlebound PAHs in a Roadway Environment. Atmospheric Pollution Research. 2015; 6(6): 1024-1034.

[3] Li JG, Yang J, Cui SG, Geng LH. Speed Limitation of a Mobile Robot and Methodology of Tracing Odor Plume in Airflow Environments. Jounal Elsevier Procedia Engineering. 2011; 15: 1014-1045.

[4] Akinyemi ML, Emetere ME, Akinwumi SA. Dynamics of Wind Strength and Wind Direction on Air Pollution Dispersion. Asian Journal of Applied Sciences. 2016; 4(2): 422-429.

[5] Rahimi MR, Hajighasemi S, Sanaei D. Designing and Simulation for Vertical Moving Control of UAV. International Journal of Electrical and Computer Engineering (IJECE). 2013; 3(5): 651-659.

[6] M Rivai, Rendyansyah, D Purwanto. Implementation of Fuzzy Logic Control In Robot Arm For Searching Location of Gas Leak. International Seminar on Intelligent Technology and Its Application. Surabaya. 2015: 69-74.

[7] K. Harrington, N. Daniel, R. Gurka, A. Harari, G.Z.A. Liberzon. Moth-Inspired Navigation Algorithm in a Turbulent Odor Plume From a Pulsating Source. PLOS ONE, 2018; 13(6): 1-18.

[8] Abusaloua A, Sheliq R. Dispersion Models of Atmospheric Air Pollutants. University Bulletin. 2016; 18(3): 56-79.

[9] Zhang T, Li H, Wang S. Inversely Tracking Indoor Airborne Particles to Locate Their Release Sources. Atmospheric Environment. 2012; 55(3): 328-338.

[10] Lu TF. Indoor Odour Source Localisation Using Robot: Initial Location and Surge Distance Matter. Robotics and Autonomous Systems. 2013; 61: 637-647.

[11] Voges N, Chaffiol A, Lucas P, Martinez D. Reactive Searching and Infotaxis in Odor Source Localization. PLOS Computational Biology. 2014; 10(10): 1-14. 
[12] Zhang J, Gong D, Zhang Y. A Niching PSO Based Multi Robot Cooperation Method for Localizing Odor Sources. Neurocomputing. 2013; 123: 308-317.

[13] Jatmiko W, Jovan F. Robots Implementation For Odor Source Localization Using PSO Algorithm. World Scientific and Engineering Academy and Society. 2011; 4(10): 115-125.

[14] Tan Y, Zheng Z. Research Advance in Swarm Robotics. Defence Technology. 2013; 9(1): 18-39.

[15] Chen B, Zhu YQ, Yi Z, Qin M, Huang QA. Temperature Effects on the Wind Direction. Sensors. 2015; 15(12): 29871-29881.

[16] Hultmark M, Smits AJ. Temperature Corrections for Constant Temperature and Constant Current Hot Wire Anemometers. Measurement Science And Technology. 2010; 21: 1-4.

[17] Zhu Y, Chen B, Qin M, Huang QA. 2 D Micromachined Thermal Wind Sensors A Review. IEEE Internet of Things Journal. 2014; 1(3): 216-232.

[18] Khamshah N, Abdalla AN, Koh SP, Rashag HF. Issues and Temperature Compensation Techniques for Hot Wire Thermal Flow Sensor: A Review. International Journal of the Physical Sciences. 2011; 6(14): 3270-3278.

[19] Kamiński Z, Czyż Z. The Characteristics of The Operating Parameters of The Vertical Axis Wind Turbine For The Selected Wind Speed. Advances in Science and Technology Research Journal. 2017; 11(1): 58-65.

[20] Yong TH, Dol SS. Design and Development of Low-Cost Wind Tunnel for Educational Purpose. Materials Science and Engineering. 2015; 78: 1-11.

[21] Garvey L, Hassan L, Nichols K, Paquin A. Equine Lung Function Testing Device. In Northeast Bioengineering Conference. Philadelphia. 2017.

[22] Prohasky D, Watkins S. Low Cost Hot-element Anemometry Verses the TFI Cobra. In 19th Australasian Fluid Mechanics Conference. Melbourne. 2014: 260-263.

[23] Panchal G, Ganatra A, Kosta YP, Panchal D. Behaviour Analysis of Multilayer Perceptrons with Multiple Hidden Neurons and Hidden Layers. International Journal of Computer Theory and Engineering. 2011; 3(2): 332-337.

[24] M Rivai, F Budiman, D Purwanto, J Simamora. Meat Freshness Identification System Using Gas Sensor Array And Color Sensor In Conjunction With Neural Network Pattern Recognition. Journal of Theoretical and Applied Information Technology. 2018, 96 (12): 3861-3872.

[25] M Rivai, A Arifin, EI Agustin. Mixed Vapour Identification Using Partition Column-QCMs And Artificial Neural Network. International Conference on Information, Communication Technology and System. Surabaya. 2016: 172-177.

[26] Rao CS. Design of Artificial Intelligent Controller for Automatic Generation Control of Two Area Hydrothermal System. International Journal of Electrical and Computer Engineering. 2012; 2(2): 183-190. 